\title{
Perceptual integration of motion and form information: Evidence of parallel-continuous processing
}

\author{
ADRIAN vON MÜHLENEN and HERMANN J. MÜLLER \\ University of Leipzig, Leipzig, Germany
}

\begin{abstract}
In three visual search experiments, the processes involved in the efficient detection of motion-form conjunction targets were investigated. Experiment 1 was designed to estimate the relative contributions of stationary and moving nontargets to the search rate. Search rates were primarily determined by the number of moving nontargets; stationary nontargets sharing the target form also exerted a significant effect, but this was only about half as strong as that of moving nontargets; stationary nontargets not sharing the target form had little influence. In Experiments 2 and 3, the effects of display factors influencing the visual (form) quality of moving items (movement speed and item size) were examined. Increasing the speed of the moving items $(>1.5 \% / \mathrm{sec})$ facilitated target detection when the task required segregation of the moving from the stationary items. When no segregation was necessary, increasing the movement speed impaired performance: With large display items, motion speed had little effect on target detection, but with small items, search efficiency declined when items moved faster than $1.5 \%$ sec. This pattern indicates that moving nontargets exert a strong effect on the search rate (Experiment 1) because of the loss of visual quality for moving items above a certain movement speed. A parallel-continuous processing account of motion-form conjunction search is proposed, which combines aspects of Guided Search (Wolfe, 1994) and attentional engagement theory (Duncan \& Humphreys, 1989).
\end{abstract}

A common assumption of many theories of visual selective attention is that objects in the visual field compete with one another for access to detailed visual processing and/or control of behavior. The visual search paradigm, in which the participant has to detect a single target object in an array of multiple nontarget objects, has become a key test for alternative theories of competition. Search performance reflects how easily competition among the multiple display items is resolved in favor of the target (e.g., Duncan, 1995). The present study is concerned with the mechanisms underlying a particular type of easy conjunction search: search for a motion-form conjunction target. McLeod and his colleagues (Driver \& McLeod, 1992; McLeod, Driver, \& Crisp, 1988; McLeod, Driver, Dienes, \& Crisp, 1991) proposed a two-stage account of motion-form conjunction search, with a motion filter that segregates the moving from the stationary items operating at the first stage, followed by parallel search of the moving items at the second stage. Similar two-stage accounts have been proposed to explain other types of effi-

This research was supported by a Swiss National Science Foundation fellowship to A.v. M. and Science and Engineering Research Council (U.K.) Grant GR/H/54966 to H.J.M. The experiments were carried out at the Department of Psychology, Birkbeck College (University of London), London. Correspondence concerning this article should be addressed to A. von Mühlenen, Institut für Allgemeine Psychologie, Universität Leipzig, Seeburgstr. 14-20, 04103 Leipzig, Germany (e-mail: vonmuehlenen@uni-leipzig.de). cient conjunction search (e.g., Egeth, Virzi, \& Garbart, 1984; Kaptein, Theeuwes, \& Van der Heijden, 1995; Nakayama \& Silverman, 1986). Although the idea of motion-based filtering is not controversial, precisely how the filtering works is not well understood (see the Issues in Motion-Form Conjunction Search section, below). The present experiments were designed to address this issue by examining the effects of the ratio and composition of moving and stationary items, item size, and speed of movement on motion-form conjunction search. Although not inconsistent with the notion of a motion filter, the results favor an account of motion-form conjunction search according to which all items sharing target features influence selection in a parallel-continuous (rather than in a discrete, all-or-nothing) fashion. Such an account may be implemented within a relatively simple eclectic framework that combines aspects of various general theories of visual search (e.g., Duncan \& Humphreys, 1989; Treisman \& Sato, 1990; Wolfe, 1994). ${ }^{1}$

\section{Efficient Search for Motion-Form Conjunctions}

One of the most influential recent accounts of visual attention and selection has been provided by Treisman's feature integration theory (FIT; Treisman \& Gelade, 1980; Treisman \& Sato, 1990). FIT has used the analysis of search reaction times (RTs) as a function of the number of items in the display (the display size [DS]) as its major tool. Two different patterns of RT/DS functions are typically observed. Which pattern is found depends on the na- 
ture of the target and nontarget objects. When the search involves a target that differs from the nontargets in a single salient feature (e.g., a vertical line among horizontal lines), the search RT functions are essentially flat, supporting the notion that targets are detected by a spatially parallel process. In contrast, when the target is defined by a conjunction of features, each of which is separately present among the nontarget items (e.g., a red X among red Os and green Xs), the search RT functions increase linearly, and the slope ratios between negative (targetabsent) and positive (target-present) responses are approximately $2: 1$. This pattern has been taken as indicative of a spatially serial, item-by-item search process, where search is exhaustive on negative trials and self-terminates upon detecting a target on positive trials. According to FIT, serial search is required in order to conjoin the separable features present at a location, which involves focal attention.

However, a number of studies (e.g., McLeod et al., 1988; Nakayama \& Silverman, 1986) have demonstrated that not all conjunction searches require serial scanning of display items, posing a problem to classical FIT (Treisman \& Gelade, 1980). In particular, McLeod et al. (1988) reported that targets defined by a conjunction of movement and form can be detected in parallel. In the task used by McLeod et al. (1988), participants had to search for a moving $\mathrm{X}$ among moving Os and stationary Xs. To account for the flat search RT functions, McLeod et al. (1988) proposed a two-stage process. At the first stage, a movement filter, operating in parallel, segregates the display into two sets, moving and stationary items. The filter represents only the moving items. At the second stage, the moving items are searched. Since there is only one moving $X$ among the moving Os represented by the filter, the task is effectively reduced to the detection of a singlefeatural form difference between the target and the nontargets, permitting the search to operate in parallel. There are other exceptions to classical FIT. For example, targets defined by stereoscopic depth and form can be detected in parallel (Nakayama \& Silverman, 1986), and display items can be segregated efficiently on the basis of color, permitting search for a color-form conjunction target to be restricted to items sharing the target color (see, e.g., Egeth et al., 1984; Kaptein et al., 1995). In brief, display items may also be segmented in parallel on the basis of depth, color, and so forth, in addition to the motion-based segmentation demonstrated by McLeod and his colleagues.

To accommodate these exceptions, Treisman and Sato (1990) proposed an augmented version of FIT. Treisman's original theory suggested that features such as movement and form, which are represented in separate feature maps, require for their correct conjunction the serial allocation of focal attention to locations specified in a master map. The main modification in the revised theory is that, if a feature distinction is particularly salient, detector units in nontarget feature maps can inhibit nontarget locations on the master map, so that they can be excluded from serial search. In other words, in a search for con- junctions of motion and form, scanning would effectively be restricted to the moving stimuli, and a parallel search would result. A very similar proposal is made by Guided Search (Cave \& Wolfe, 1990; Wolfe, 1994; Wolfe, Cave, \& Franzel, 1989), except that potential target locations on the master map receive excitation from target-compatible feature maps (rather than the nontarget locations' receiving inhibition from target-incompatible feature maps). Attentional engagement theory (Duncan \& Humphreys, 1989,1992 ) can also explain the parallel search for conjunctions of motion and form by assuming that stationary items are assigned negligible selection weights, so that they would barely disrupt search despite sharing the target's form.

\section{Issues in Motion-Form Conjunction Search}

Thus, the existence of some form of motion-based filtering is not controversial and can be accommodated by most general theories of visual search (see note 1). However, precisely how the motion-based filtering works is not well understood, and there are at least two unresolved, interrelated empirical issues. (1) Can stationary items-in particular, items sharing the target form-be effectively kept out of the search for a moving target, or is motionbased filtering leaky? (2) Is the target form discriminated within the motion system, as was proposed by McLeod and his colleagues, or is it discriminated within a unitary form system that represents both moving and stationary items? The answers to these questions are potentially important for deciding between alternative accounts or, at least, classes of accounts of motion-form conjunction search (see also Driver \& McLeod, 1992; Duncan, 1995) and, perhaps, between accounts of efficient conjunction search in general (assuming that the principles that have evolved to support motion-based segmentation may also underlie depth-based segmentation, etc.).

Is motion-based filtering leaky? Driver and McLeod (1992) put forward the strong assumption of a nonleaky movement filter. This would require that the search RT functions are completely unaffected by the stationary items. However, the search RT function slopes for positive trials in the experiments of McLeod and his colleagues, as well in our own motion-form conjunction search experiments (e.g., von Mühlenen, 1997), were never completely flat- that is, the search rates calculated on the basis of the total number of display items were never zero. Calculating the search rates in this way implicitly assumes that all the types of display items contribute equally to performance. However, it is possible that search rates are primarily determined by the stationary nontargets sharing the target form, in which case one might conclude that filtering by motion is leaky; or search rates may be primarily determined by the moving nontargets, in which case one might conclude that search across the moving items is not parallel. Therefore, accounts of motion-form conjunction search based on averaged search rates can be potentially misleading. To resolve this issue, Experiment 1 was designed to dissociate the contributions of the 
two types of nontarget items to the search rates, by systematically varying their proportion. The major finding was that stationary nontargets sharing the target form exerted a significant influence on the search rate, consistent with leaky motion-based filtering. However, moving nontargets were the single most important determinant of the search rate.

Is visual form discriminated within the motion system? The finding that moving items so strongly influence the search rate bears on the second issue: Is the target form discriminated within the motion system, or is it discriminated within a unitary form system that represents both the stationary and the moving items? Driver and McLeod (1992) and Berger and McLeod (1996) argued that gross aspects of form are discriminated within the motion filter. This proposal was based on their finding that, when the form discrimination required was easy, moving search was more efficient than stationary search, but when the discrimination was difficult, stationary search was more efficient than moving search. However, Müller and Maxwell (1994) and Müller and Found (1996) failed to observe such an asymmetry reversal and argued that it is more parsimonious to assume that there is a unitary form system representing both the stationary and the moving items, although the latter have a degraded visual quality (see also Müller \& von Mühlenen, 1999). Loss of visual quality for the moving items (above a certain movement speed) could also explain why moving nontargets so strongly influenced the search rate in Experiment 1, since a loss of quality would make the form discrimination between a moving nontarget and a moving target more difficult. An alternative account is that, for moving items, the cross-referencing of corresponding motion and form signals is unreliable when items move in close proximity to one another; that is, it may be difficult to appropriately bind form and motion features, leaving the possibility of illusory conjunctions (Treisman \& Gelade, 1980). Experiments 2 and 3 were designed to examine these alternatives by systematically varying the movement speed and size of the display items (affecting their visual quality), while keeping constant the item density (affecting the reliability of cross-referencing). The results were consistent with the account of a loss of visual quality for the moving items.

\section{EXPERIMENT 1}

In our previous study of motion-form conjunction search (von Mühlenen \& Müller, 1999), ${ }^{2}$ the search rates on positive trials ranged between 10 and $15 \mathrm{msec} /$ item, which is somewhat slower than the search rates observed by McLeod et al. (1988; McLeod et al., 1991) under similar conditions. Slopes of 10-15 msec/item could be described as borderline parallel or, in terms of Wolfe (1998), as approaching "quite efficient search." However, to belittle such rates as being borderline parallel may well run the risk of neglecting display factors that prevent perfect parallel search, factors that are potentially important for a full account of motion-form conjunction search.

In motion-form conjunction search, all the items that share target attributes are potentially important in determining the search rate. The calculation of the search rates in previous experiments (McLeod et al., 1988; McLeod et al., 1991) was, in some sense, arbitrary, based on functions relating the search RTs to the total number of items in the display. However, on the basis of a strong movement filter account (which assumes a nonleaky filter), search rates should be calculated from the function relating RTs to the moving items only (because stationary items are not represented in the filter). For the displays used by McLeod and his colleagues, this would mean that the search rates should be doubled, because, in their display, only half of the items were moving. By contrast, calculating search rates on the basis of all the items presupposes that all the items are equally important. There is some evidence (Müller \& Maxwell, 1994) suggesting that stationary items do influence search for motion-form conjunctions (contrary to a strong motion filter account). However, there are, as of yet, no hard data quantifying to what extent they contribute to the search rates and to what extent their contribution is additive to that of the moving items. Experiment 1 was designed to provide this information.

In previous work (McLeod et al., 1988; McLeod et al., 1991; von Mühlenen \& Müller, 1999), both the moving Os and the stationary Xs may have contributed to the search rates. In terms of the logic of conjunction search, both may be expected to influence search efficiency, because they both share one target-defining attribute (movement or X-form). For the same reason, it may be assumed that stationary Os (which were not presented in the previous experiments) would exert relatively little influence on search efficiency, since they share no attribute with the target. Experiment 1 was designed to determine the relative contribution of these variables (numbers of moving Os, stationary $\mathrm{Xs}$, and stationary Os) to the search rate, under display conditions similar to those in our previous experiments (von Mühlenen \& Müller, 1999).

\section{Method}

Participants. Six participants, 3 women and 3 men, took part in Experiment 1 . Their ages ranged from 17 to 31 years. They all had normal or corrected-to-normal vision. They were paid $£ 4$ per hour. All the participants received thorough practice on the task in one or more preexperimental sessions (of 720 trials).

Apparatus. The stimuli were presented on a Tektronix $608 \mathrm{X}-\mathrm{Y}$ monitor (CRT) with a fast-decay P15 phosphor. The CRT was driven by an Interactive Electronics Systems point plotter (Finley, 1985 ), controlled by a Dell $433 / \mathrm{M} \mathrm{PC}$. The participants viewed the CRT from a distance of $33 \mathrm{~cm}$, with the viewing distance maintained through the use of a chinrest. At this distance, the total screen area subtended approximately $22^{\circ} \times 16^{\circ}$ of visual angle. The laboratory was dimly illuminated, to eliminate reflections on the CRT. The participants' responses (target present or absent) were recorded by using the right and left buttons of a serial Microsoft mouse, with 


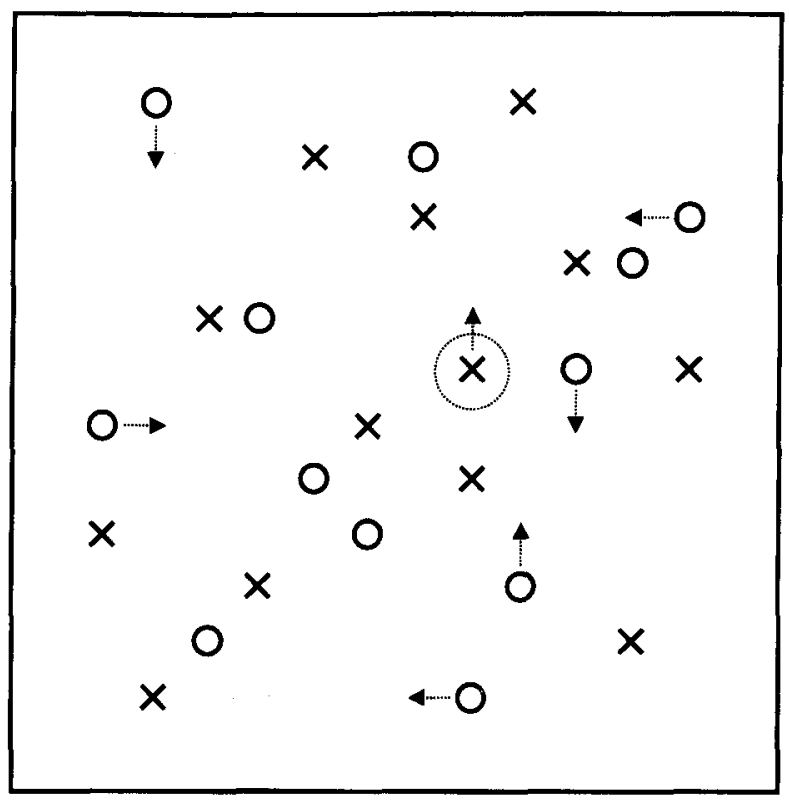

Figure 1. Example of a display used in Experiment 1. The display contains 25 items moving in four orthogonal directions (movement direction indicated by dotted arrows). The target is a moving $X$ among moving $O s$, stationary $X s$, and stationary $O s$ (note that stationary $O$ s were presented only in Conditions 1,2 , and 4, detailed in Table 1).

the track ball removed to improve timing accuracy (Segalowitz \& Graves, 1990).

Stimuli. A trial started with the presentation, for $500 \mathrm{msec}$, of a fixation cross in the center of the display (line size, $1^{\circ}$ ). There was then a $500-\mathrm{msec}$ blank interval, followed by a display of stationary and moving items. The display stayed on until either the participant responded or the maximum display duration of $2,440 \mathrm{msec}$ was reached. Responses were timed from the onset of the display. The intertrial interval was $1,500 \mathrm{msec}$.

The participants searched for a moving $\mathrm{X}$ in displays consisting of various item combinations of moving Os, stationary Xs, and stationary Os (see Figure 1). The DS was 9, 17, or 25 items, including the target on positive trials. The moving items moved in four orthogonal directions (left, right, up, down), with the direction of the target being determined pseudorandomly on positive trials. ${ }^{3}$ The position of each moving item was incremented every $20 \mathrm{msec}$ by $0.044^{\circ}$, which produced the impression of a smooth continuous motion (movement speed of $2.2^{\circ}$ per second). Displays were shown for a maximum time of $2,440 \mathrm{msec}$, during which the moving items could cover a distance of $5.4^{\circ}$. Otherwise, displays were terminated by the participant's response.

The stimuli were crosses rotated by $45^{\circ}(\mathrm{Xs})$ and circles $(\mathrm{Os})$, both $0.36^{\circ}$ in height and width. ${ }^{4}$ For each display, the starting position and movement direction of each item were determined individually. This was done by dividing the display into an invisible square matrix with cells of size $1.35^{\circ} \times 1.35^{\circ}$. The size of the matrix decreased with decreasing DS, so that the relative density of the display items would be reasonably constant. With 25 -item displays, the display area was divided into $12 \times 12$ cells, with 17 -item displays into $10 \times 10$ cells, and with 9-item displays into $8 \times 8$ cells. This means that the display area increased with the number of items, being $10.8^{\circ} \times 10.8^{\circ}, 13.5^{\circ} \times 13.5^{\circ}$, and $16.2^{\circ} \times 16.2^{\circ}$ for 9 -, $17-$, and 25 -item displays, respectively. ${ }^{5}$ Note, however, that item eccentricity with respect to the display center was controlled for by presenting displays containing less than the maximum number of items at random positions within the maximum display area. For example, 9 -item displays $\left(10.8^{\circ} \times 10.8^{\circ}\right.$ display area) could be placed at any position within the confines of the maximum display area $\left(16.2^{\circ} \times 16.2^{\circ}\right)$. This is a two-dimensional variant of the procedure used by McLeod et al. (1988) for the horizontal display dimension. Moving items moved on horizontal and vertical tracks, traversing in $2,440 \mathrm{msec}$ a maximum of four cells.

Forty displays (item arrangements) were generated for each DS condition $(9,17$, and 25$)$, using the following procedure. The starting coordinates of each display item on the matrix were determined randomly, except for the following constraints: (1) Only one item was permitted to occupy a cell; moving items were not permitted to (2) leave the matrix during the maximum course of the movement, (3) collide with a stationary item or other moving items, or (4) move in tandem with another item on the same track in the same direction without being separated by at least one cell. If one of these criteria was violated, new coordinates were randomly chosen until all the criteria were met. Stationary items were placed first, and moving items second. For the latter, the direction of movement was changed after each valid placement of an item. All the item coordinates were generated in advance (i.e., they were the same for all the participants).

The numbers of moving Os and stationary Xs were systematically varied. Whenever required, stationary Os were added to the display as filler elements, to hold the DS constant at 9,17 , or 25 items (for the reasons stated above, stationary Os were expected to have relatively little influence on search efficiency). Although Experiment 1 was concerned with the effects of the number of moving Os and stationary Xs, display conditions will be described in terms of the proportions of these items, because the proportions are independent of DS. Displays consisted of varying proportions of stationary $X$ and moving $O$ nontarget items: $25 \%, 50 \%$, and $75 \%$ (see Table 1). However, it was logically impossible to vary the proportions of stationary Xs and moving Os orthogonally, because there cannot be displays containing high proportions of both types of item (that would add up to more than $100 \%$ ). This constraint excluded three of the nine $(3 \times 3)$ factorial-combination conditions in the design of Experiment 1 (see the empty cells in Table 1). The six remaining display compositions are numbered from 1 through 6 (see the numbers in Table 1). For example, in Condition 1, displays consisted of $25 \%$ stationary Xs and $25 \%$ moving Os (topped by $50 \%$ stationary Os); in Condition 6 , there were $25 \%$ stationary Xs and $75 \%$ moving Os (without any stationary Os). The displays were essentially the same on negative trials, except that the target item (a moving $X$ ) was replaced by a moving $O$. The number of movement directions was held constant at four, with the same number of nontargets moving in each direction.

Design and Procedure. There were 40 trials for each combination of display composition, DS, and target (present, absent), giving a total number of $(6 \times 3 \times 2 \times 40=1,440$ trials, excluding practice trials at the beginning of the experiment and warm-up tri-

Table 1

Proportions of Moving Os (MO) and Stationary Xs (SX) of the Total Number of Distractors in the Six Display Composition Conditions (Numbered 1 to 6) of Experiment 1

\begin{tabular}{cccc}
\hline & \multicolumn{3}{c}{ Proportion of SX } \\
\cline { 2 - 4 } Proportion of MO & $25 \%$ & $50 \%$ & $75 \%$ \\
\hline $25 \%$ & $1^{*}$ & $2^{*}$ & 3 \\
$50 \%$ & $4^{*}$ & 5 & - \\
$75 \%$ & 6 & - & - \\
\hline
\end{tabular}

*Stationary Os were added in these conditions to keep display size constant at 9,17 , or 25 items. 


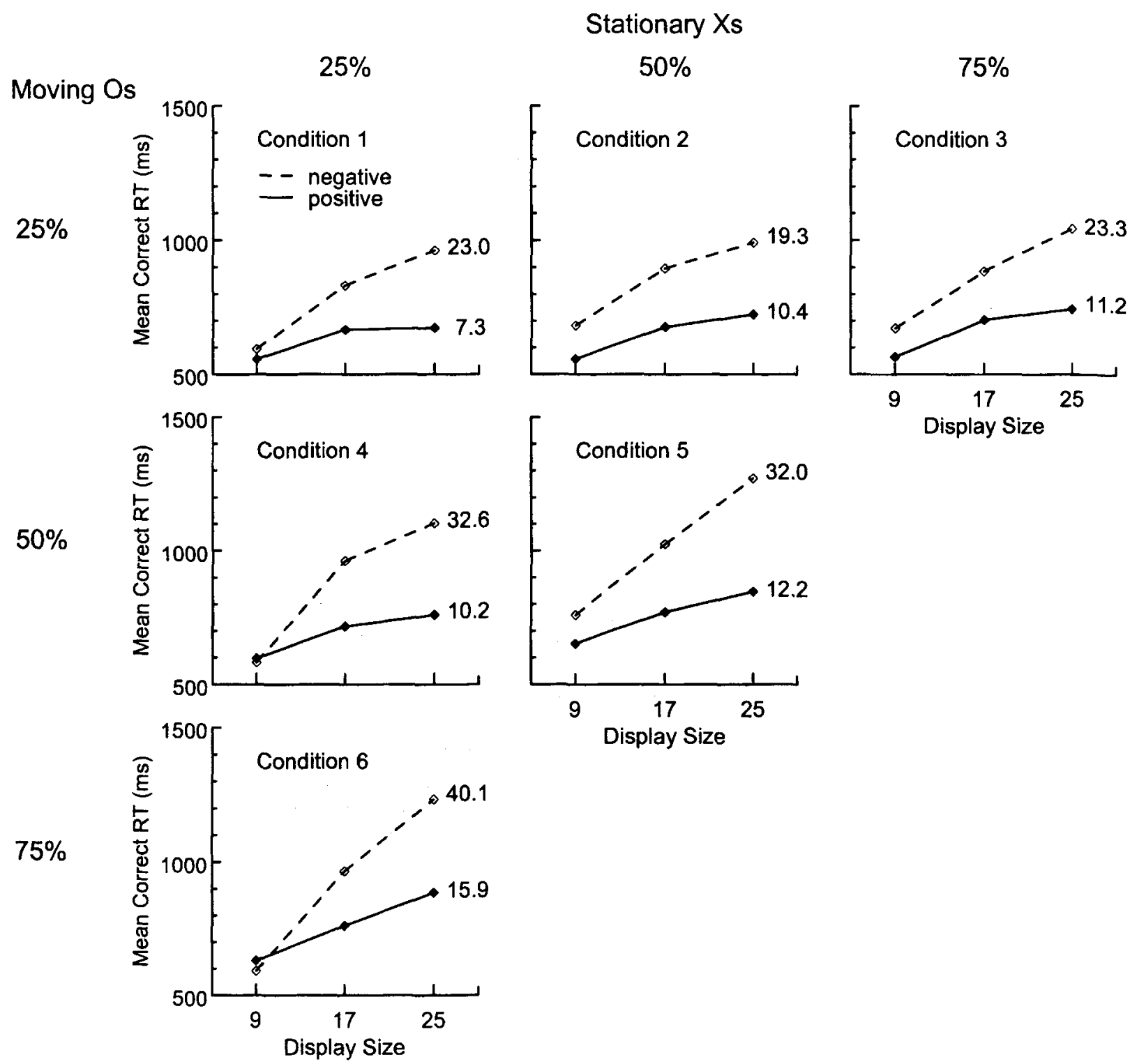

Figure 2. Mean correct reaction times (RTs) for positive and negative trials as a function of the display size in Experiment 1 . The graphs are arranged analogously to the variation in the proportions of stationary Xs and moving Os, detailed in Table 1.

als at the beginning of each block. All combinations of display composition, DS, and target were presented in randomized order. The 1,440 trials were presented to the participants in two sessions, each subdivided into 12 blocks of 60 trials.

Instruction. The participants initiated a block by pressing one of the mouse buttons. To each display, the participants had to make the appropriate response according to whether the target was absent or present. The participants were instructed to react as quickly and accurately as possible. If the participants made an error, they were alerted to this event by a computer-generated bleep.

\section{Results}

Reaction time data. Figure 2 presents the mean positive- and negative-trial search RTs for the six display compositions as a function of overall DS. The graphs are arranged analogously to the variation in the proportions of stationary Xs and moving Os, detailed in Table 1. The means of the search rate estimates calculated individually for each participant are provided on the right of each graph. Figure 2 shows that the search rates increased with both the proportion of stationary Xs and the proportion of moving Os, with the latter exerting a comparatively greater effect.

Multiple regression analysis. The relative contribution of moving $\mathrm{O}$ and stationary $\mathrm{X}$ nontargets to the search rate was estimated, using a multiple linear analysis approach. The analysis was performed in two stages. In the first stage, a simple additive model was tested, according to which each type of nontarget exerted an indepen- 
Table 2

Summary of Stepwise Regression Analysis With Moving Os (MO), Stationary Xs (SX), and Stationary Os (SO) Predicting the RT for Positive Trials in Experiment 1

\begin{tabular}{lrrr} 
Variable & $B$ & $S E$ for $B$ & $\beta$ \\
Step 1 $\left(R^{2}=.74\right)$ & & & \\
MO & 15.63 & 2.29 & $.86^{+}$ \\
Step 2 $\left(R^{2}=.94\right)$ & & & \\
MO & 16.07 & 1.13 & $.89^{+}$ \\
SX & 8.05 & 1.13 & $.44^{+}$ \\
Step 3 $\left(R^{2}=.96\right)$ & & & \\
Constant & 522.88 & 13.02 & \\
MO & 16.85 & 1.03 & $.93^{+}$ \\
SX & 8.82 & 1.03 & $.49^{\dagger}$ \\
SO & 3.04 & 1.22 & $.15^{+}$ \\
\hline Step 4 $\left(R^{2}=.97\right)$ & & & \\
Constant & 538.74 & 13.52 & \\
MO & 13.74 & 1.66 & $.76^{+}$ \\
SX & 5.72 & 1.66 & $.32^{+}$ \\
SO & 2.84 & 1.08 & $.14^{*}$ \\
MO $\times$ SX & 0.63 & 0.28 & $.26^{*}$ \\
\hline
\end{tabular}

Note-Steps 1-3 were tested main effects only; Step 4 was tested additional interaction effects. $R^{2}=.74$ for Step 1; $\Delta R^{2}=.20$ for Step 2, $F(1,15)=50.35, p<.01 ; \Delta R^{2}=.02$ for Step $3, F(1,14)=6.21, p<.05$; $\Delta R^{2}=.01$ for Step $4, F(1,13)=5.38, p<.05 . B$, regression weight. ${ }^{*} p<.05 . \quad \dagger p<.01$.

dent influence of a particular weight on the search rate. More formally, this model assumes that the RT taken to respond to the presence or absence of a target is a linear function of the numbers of moving Os (MO), stationary Xs (SX), and stationary Os (SO),

$$
\mathrm{RT}=A+B_{1} \mathrm{MO}+B_{2} \mathrm{SX}+B_{3} \mathrm{SO}
$$

where $A$ is a constant, and $B_{1}, B_{2}$, and $B_{3}$ are the weights of influence on RT of each type of display item. This model was tested in stepwise linear regression analyses performed separately for positive- and negative-trial RTs. Both analyses used a forward selection strategy, starting without variables in the equation, entering the most significant predictor in the first step, and then continuing to add and delete variables until the amount of variance explained no longer improved significantly ( $\alpha$ to-enter was set to $.05, \alpha$-to-remove to .10 ).

The results are summarized in the top halves of Table 2 (RTs for positive trials) and Table 3 (RTs for negative triais). For positive-trial RTs, the first variable selected by the stepwise regression procedure described above was MO, accounting for $74 \%$ of the variance. The next variable selected was SX, increasing the amount of explained variance to $94 \%$. Finally, SO was selected, which increased the amount of explained variance only very little, to $96 \%$. In terms of the final regression weights $(B)$, each moving $O$ in the display contributed twice as much to the search RT as each stationary $\mathrm{X}(16.9 \mathrm{vs} .8 .8 \mathrm{msec})$; a stationary $\mathrm{O}$, by contrast, contributed relatively little $(3.0 \mathrm{msec})$. For negative-trial RTs, the selection order of variables was the same: MO, SX, and SO. The amount of variance explained in each successive selection step was $51 \%$ in Step $1(\mathrm{MO}), 82 \%$ in Step $2(\mathrm{MO}+\mathrm{SX}$ ), and $92 \%$ in Step $3(\mathrm{MO}+\mathrm{SX}+\mathrm{SO})$. Again, each moving O contributed more to the search RT than did each stationary $X(34.7 \mathrm{vs} .26 .8 \mathrm{msec})$, whereas a stationary $O$ contributed less $(16.5 \mathrm{msec})$. On this simple model, one would conclude that-in addition to MO-SX and SO are significant predictors of RT, consistent with the hypothesis of a leaky motion filter. ${ }^{6}$

A second stage of analysis was performed that permitted interaction effects to enter the regression equation (in addition to main effects). The results are summarized in the bottom halves of Table 2 (positive trials) and Table 3 (negative trials). For both positive- and negative-trial $\mathrm{RTs}$, only the MO $\times \mathrm{SX}$ interaction met the criterion $(\alpha<$ .05 ) to enter the equation [positive trials, $F(1,13)=4.96$, $p<.05$; negative trials, $F(1,13)=5.83, p<.05$ ]. Inclusion of this interaction term increased the amount of variance explained significantly, for positive trials $\left[\Delta R^{2}=.01\right.$, $F(1,13)=5.38, p<.05]$ and for negative trials $\left[\Delta R^{2}=.03\right.$, $F(1,13)=6.02, p<.05]$. "Forced" entry of other interactions did not significantly increase the amount of variance explained. As was expected, including the $\mathrm{MO} \times \mathrm{SX}$ interaction in the regression equation somewhat diminished the $B$ (and $\beta$ ) coefficients of the other variables. However, all three main effects remained significant for both the positive- and the negative-trial analyses, and the amount of variance explained by the more complex model increased only little, relative to the simple model (for positive trials, $97 \%$, as compared with $96 \%$; for negative trials, $96 \%$, as compared with $92 \%$ ).

Error data. The false-alarm rates were relatively low, $1.5 \%$ overall, and were little affected by display composition and DS, although there was a tendency for falsealarm rates to be somewhat increased with small displays $(\mathrm{DS}=9$ ) and few moving Os (an average of $3.5 \%$ false

Table 3

Summary of Stepwise Regression Analysis With Moving Os (MO), Stationary Xs (SX), and Stationary Os (SO) Predicting the RT for Negative Trials in Experiment 1

\begin{tabular}{lccc} 
Variable & $B$ & $S E$ for $B$ & $\beta$ \\
\hline Step l $\left(R^{2}=.51\right)$ & & & \\
MO & 29.22 & 7.14 & $.72^{+}$ \\
Step 2 $\left(R^{2}=.82\right)$ & & & \\
MO & 30.46 & 4.52 & $.75^{+}$ \\
SX & 22.60 & 4.52 & $.55^{+}$ \\
Step 3 $\left(R^{2}=.92\right)$ & & & \\
Constant & 449.97 & 40.82 & \\
MO & 34.68 & 3.22 & $.85^{+}$ \\
SX & 26.83 & 3.22 & $.66^{+}$ \\
SO & 16.48 & 3.82 & $.35^{*}$ \\
\hline Step 4 $\left(R^{2}=.95\right)$ & & & \\
Constant & 502.62 & 41.42 & \\
MO & 24.37 & 5.10 & $.60^{+}$ \\
SX & 16.51 & 5.10 & $.40^{+}$ \\
SO & 15.84 & 3.30 & $.34^{*}$ \\
MO $\times$ SX & 2.09 & 0.87 & $.38^{*}$ \\
\hline
\end{tabular}

Note--Steps 1-3 were tested main effects only; Step 4 was tested additional interaction effects. $R^{2}=.51$ for Step $1 ; \Delta R^{2}=.31$ for Step 2, $F(1,15)=25.03, p<.01 ; \Delta R^{2}=.10$ for Step 3, $F(1,14)=18.62, p<$ $.01 ; \Delta R^{2}=.03$ for Step $4, F(1,13)=6.02, p<.05 . B$, regression weight. ${ }^{*} p<.05 . \quad \dagger p<.01$. 
alarms). The miss rates were higher overall, $5.2 \%$, and they increased with DS, from $3.1 \%$ for DS $=9$ to $7.0 \%$ for $\mathrm{DS}=25$, and with the proportion of moving Os, from $2.7 \%$ for $\mathrm{MO}=25 \%$ to $8.2 \%$ for $\mathrm{MO}=75 \%$. To summarize, only moving Os produced an increase in the error rate, which is in line with the pattern of results for RTs.

\section{Discussion}

In summary, Experiment 1 clearly showed the number of moving Os to be the single most important predictor of search efficiency. However, the number of stationary Xs was also important, particularly for negative-trial RTs, perhaps owing to stationary Xs' being rechecked on negative trials. The number of stationary Os was least important. This pattern is consistent with an account of motion-form conjunction search according to which all display items influence search efficiency in a parallelcontinuous, rather than an all-or-nothing, manner, with their weight reflecting how target-like the various types of nontarget are. Stationary nontarget items can be kept out of the search relatively efficiently, particularly items not sharing target attributes. This is consistent with a leaky motion filter account.

The second regression analysis revealed the interaction term between the numbers of moving Os and stationary $\mathrm{Xs}$ to be an important determinant of search RT. This interaction means that there is an extra RT cost when moving Os and stationary Xs are presented together in a display. The resulting cost is at a maximum when the proportions of moving Os and stationary $\mathrm{Xs}$ are equal but is reduced when the proportions are unequal. This pattern is reminiscent of the distractor ratio effects observed by Zohary and Hochstein (1989) and Poisson and Wilkinson (1992). These authors reported that, in conjunction searches involving color, such as a search for a red horizontal bar target among green horizontal bar $\left(D_{1}\right)$ and red vertical bar $\left(D_{2}\right)$ distractors, the search efficiency depended on the ratio between the two types of distractors: the more unequal the $D_{1}: D_{2}$ ratio, the more efficient the search. Zohary and Hochstein took this pattern to suggest that only one type of distractor, the less numerous type, is scanned. This implies that the scanning strategy is adaptive, based on some measurement of the relative numbers of the two types of distractors derived after the parallel representation and segmentation of the various display elements. The significant $\mathrm{MO} \times \mathrm{SX}$ interaction in the present experiment indicates that motion-form conjunction search uses an adaptive mechanism similar to that employed by color-form conjunction search.

In model terms, motion -form conjunction search might proceed along the following lines. Candidate targets are selected from an overall activation (saliency) map that is computed by integrating bottom-up activation from the form and motion systems. All the moving items receive (top-down) enhancement via the motion system, and all the Xs receive (top-down) enhancement via the form system (moving items and Xs are top-down enhanced because they share target features). By integrating the motion- and form-based activation maps, the target ought to receive the highest activation at the level of the overall saliency map. However, because of a loss of visual quality for the moving items, there is an increased likelihood of mistaking the moving target $\mathrm{X}$ for a moving nontarget $\mathrm{O}$ and vice versa. In other words, the moving target $\mathrm{X}$ might gain less saliency on the overall activation map, and the moving nontarget Os might gain more saliency. As a result, moving nontarget Os may be selected and, thus, may need to be rejected by the serial selection mechanism. However, stationary Xs are less likely to achieve high overall saliency (i.e., are less likely to be selected), because they receive enhanced activation only via the form system. By the same argument, stationary Os should never achieve high overall saliency, because they receive no enhanced activation whatever. (This model, and how it can incorporate an adaptive mechanism sensitive to the ratios between SX and MO, is elaborated in the General Discussion section).

Experiment 1 showed the moving Os to be the most important determinant of the search rate, without, however, providing an explanation for their strong weight. It was suggested above (in the model sketch) that this was, at least in part, due to a reduced quality of the moving items' representation in the form system, making the discrimination between a moving $O$ and a moving $X$ (the target) more difficult. This suggestion is important with regard to the debate as to whether or not "gross" aspects of form discrimination are performed within the motion system (Berger \& McLeod, 1996; Driver \& McLeod, 1992; Müller \& Found, 1996; Müller \& von Mühlenen, 1999). In the terms of Driver and McLeod, discriminating an $\mathrm{X}$ from an $\mathrm{O}$ is easy and can be performed within the motion filter-that is, it would not rely on stimulus analysis by the stationary form system. According to this account, there should be little effect of visual degradation on search efficiency as long as the discrimination required is easy. According to the alternative account sketched above, all the display items influence search efficiency in a parallel-continuous manner, and all form analysis relies on the stationary form system. Consequently, this account would predict visual degradation effects on search efficiency even for easy form discriminations.

Alternatively, moving Os may be the strongest determinant of search efficiency, since the task involves a decision that is based on a comparison of the forms of the moving items. The task of the motion system is to direct form-based comparisons within the stationary system to the moving items. This is difficult, because moving items continually change their positions, so that it is hard to cross-reference the output of motion analyzers with that of corresponding form analyzers. In other words, the cross-referencing may be unreliable (leaving the possibility of illusory conjunctions) -in particular, with items moving in multiple directions and with the target direction's being unpredictable. 


\section{A) Small Item Size}

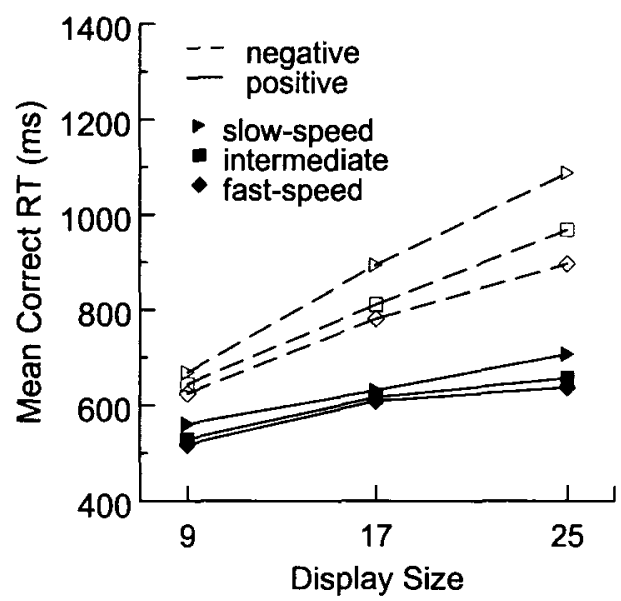

B) Large Item Size

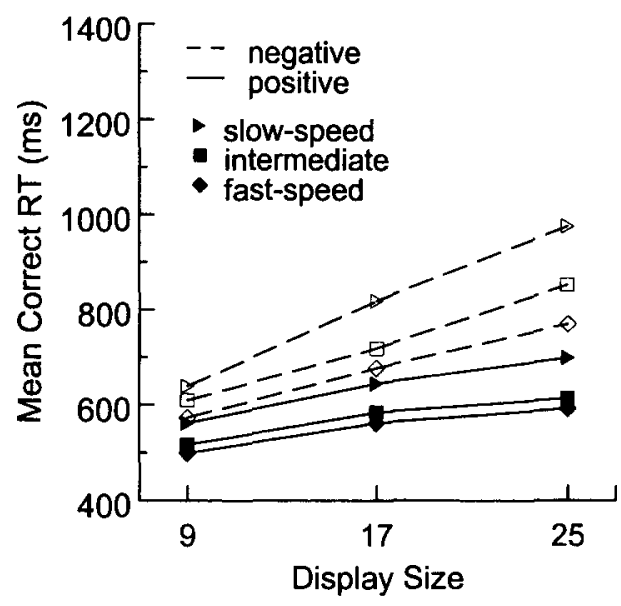

Figure 3. Mean correct reaction times (RTs) for positive and negative trials as a function of the display size, separately for each movement speed condition in Experiment 2. Figures 3A and 3B present the RTs for the small item displays and the large item displays, respectively.

\section{EXPERIMENT 2}

Experiment 2 was designed to investigate the extent to which the visual quality of the moving items affects the search rates (see the Issues in Motion-Form Conjunction Search section, issue 2). Furthermore, the numbers of stationary Xs and moving Os were equal, as in the experiments of McLeod et al. (1991), to permit a more direct comparison with their search rates (see issue 1).

Visual quality was manipulated by varying the size of the display items $\left(0.30^{\circ}\right.$ or $0.43^{\circ}$; in the previous experiments, the size was $0.36^{\circ}$ ) and the speed of the moving items, from $1.5^{\circ} / \mathrm{sec}$ through $2.25^{\circ} / \mathrm{sec}-3.0^{\circ} / \mathrm{sec}\left(2.2^{\%} / \mathrm{sec}\right.$ was the movement speed used in the previous experiments and in most of the experiments of McLeod et al., 1991). Search efficiency was expected to be greater for the larger items. Furthermore, the advantage (in search rates) for the larger items was predicted to be dependent on movement speed, because the visual degradation from fast stimulus motion was expected to affect the discriminability of smaller items relatively more than that of larger items. Note that an increase in movement speed might also be expected to facilitate the segmentation of the moving (from the stationary) items, because of increased motion contrast (i.e., the difference in speed between the moving and the stationary items). Thus, search RTs might become faster with increasing movement speed (because segmentation is facilitated); but, nevertheless, the difference in search rates between the large and the small items might increase (owing to movement-induced loss of visual quality).

\section{Method}

Participants. Six new participants, 1 woman and 5 men, took part in Experiment 2. Their ages ranged from 27 to 39 years. They all had normal or corrected-to-normal vision. They were paid $£ 4$ per hour.
Stimuli. The stimuli were the same as those in Experiment 1. The participants searched for a moving $X$ in displays consisting half of stationary Xs and half of moving Os (see Condition 5 of Experiment 1). The DSs were 9, 17, and 25 items (including the target), and the number of movement directions was four, with the same number of nontargets moving in each direction.

The size of the stimuli was varied: Items were $0.30^{\circ}$ in the smallsize and $0.43^{\circ}$ in the large-size conditions (previously $0.36^{\circ}$ ). The overall display area remained the same for both size conditions. Furthermore, the speed of the moving stimuli was varied. They had a speed of $1.5 \% \mathrm{sec}$ in the slow-speed condition, $2.25 \% \mathrm{sec}$ in the intermediatespeed condition, and $3.0 \% \mathrm{sec}$ in the fast-speed condition. The fastspeed condition made it necessary to shorten the duration for which displays were presented to $1,620 \mathrm{msec}$ (as compared with $2,440 \mathrm{msec}$ in Experiment 1), to keep the display area and item density constant across the various speed conditions. The display duration was shortened for all the speed conditions, to keep the response deadline constant. The maximum display duration of $1,620 \mathrm{msec}$ meant that the maximum distance a moving item could cover was $2.7^{\circ}$ in the slowspeed condition, $4.1^{\circ}$ in the intermediate-speed condition, and $5.4^{\circ}$ (i.e., the same as that in Experiment 1) in the high-speed condition.

Design and Procedure. There were 40 trials for each combination of item size (SZ; small, large), movement speed (SP; slow, intermediate, fast), DS $(9,17$, or 25 items), and target (TG; present, absent), giving a total number of 1,440 trials (excluding practice and warm-up trials). The experiment consisted of one practice and three testing sessions, each devoted to one of the three SP conditions and conducted on separate days. The presentation order of the SP conditions was counterbalanced across the 6 participants. Each session was divided into 10 blocks (of 48 trials each). SZ was constant within a block but alternated across blocks. Half the participants started with a block of small-item displays, the other half with a block of large-item displays.

\section{Results}

Reaction time data. Figure 3 presents the RT data separately for the small and the large item size conditions (Figures 3A and 3B, respectively). Each figure shows the function relating the positive- and the negative-trial search RTs to the total DS, separately for the slow-, the 
Table 4

Mean Base Reaction Times (RT, in Milliseconds), Search Rates (Rate, in Milliseconds/Item), and Linearity of the Search RT Functions (Mean $R^{2}$ and $S D$ ) in Experiment 2

\begin{tabular}{|c|c|c|c|c|c|c|c|c|}
\hline \multirow[b]{2}{*}{ Movement Speed } & \multicolumn{4}{|c|}{ Positive Trial } & \multicolumn{4}{|c|}{ Negative Trial } \\
\hline & RT & Rate & $R^{2}$ & $S D$ & RT & Rate & $R^{2}$ & $S D$ \\
\hline \multicolumn{9}{|l|}{ Small item size } \\
\hline Slow & 478 & 9.2 & .95 & .07 & 438 & 26.2 & .99 & .00 \\
\hline Intermediate & 465 & 8.0 & .92 & .08 & 463 & 20.3 & .99 & .01 \\
\hline Fast & 460 & 7.5 & .88 & .10 & 478 & 17.0 & .98 & .02 \\
\hline \multicolumn{9}{|l|}{ Large item size } \\
\hline Slow & 489 & 8.5 & .95 & .04 & 454 & 21.0 & .99 & .01 \\
\hline Intermediate & 468 & 6.1 & .83 & .21 & 470 & 15.1 & .96 & .05 \\
\hline Fast & 452 & 5.8 & .90 & .14 & 465 & 12.2 & .91 & .21 \\
\hline
\end{tabular}

intermediate-, and the fast-speed conditions. The corresponding mean base RTs and mean search rates are listed in Table 4.

The figures show TG (absent, present) and DS effects similar to those observed in previous work (e.g., von Mühlenen \& Müller, 1999, Experiment 1). A four-way analysis of variance (ANOVA), with main terms of TG, DS, SZ, and SP, revealed the TG and DS main effects and their interaction to be significant $[\mathrm{TG}, F(1,5)=37.30, p<$ .01 ; DS, $F(2,10)=43.64, p<.01$; TG $\times$ DS, $F(2,10)=$ $32.30, p<.01]$. RTs were faster in positive than in negative trials, and RTs increased with DS, exhibiting greater DS effects with negative-trial RTs than with positivetrial RTs.

More interesting, RTs were overall faster with largethan with small-item displays $[F(1,5)=12.85, p<.05]$, and they were faster with increased SP $[F(2,10)=20.29$, $p<.01]$. Furthermore, SZ interacted with TG and DS $[\mathrm{SZ} \times \mathrm{TG}, F(1,5)=39.54, p<.01 ; \mathrm{SZ} \times \mathrm{DS}, F(2,10)=$ $23.12, p<.01 ; \mathrm{SZ} \times \mathrm{TG} \times \mathrm{DS}, F(2,10)=4.11, p<.05]$, as did movement speed [SP $\times$ TG, $F(2,10)=6.86, p<$ $.05 ; \mathrm{SP} \times \mathrm{DS}, F(4,20)=10.20, p<.01 ; \mathrm{SP} \times \mathrm{TG} \times \mathrm{DS}$, $F(4,20)=6.94, p<.01]$

The overall RT advantage for large items was greater on negative than on positive trials ( $83 \mathrm{vs.} 21 \mathrm{msec}$; SZ main effect). This differential effect was, in part, due to an advantage in search rate for large relative to small items (SZ $\times$ DS interaction), which was more marked on negative than on positive trials (negative trials, 16.1 vs. $21.2 \mathrm{msec} /$ item; positive trials, $6.8 \mathrm{vs} .8 .2 \mathrm{msec} /$ item; $\mathrm{SZ}$ $\times$ TG $\times$ DS interaction)

Increasing SP from slow to intermediate produced a RT advantage of 17 and $46 \mathrm{msec}$ on positive and negative trials, respectively. Increasing SP from intermediate to fast produced a more marked advantage of 48 and $80 \mathrm{msec}$, respectively. Again, these effects were, in part, due to improvements in search rates, particularly on negative trials. The search rates decreased with increasing SP from 8.9 to $6.7 \mathrm{msec} / \mathrm{item}$ on positive trials and from 23.6 to $14.6 \mathrm{msec} /$ item on negative trials.

The effects of SZ were as expected: faster overall RTs and faster search rates for larger items (particularly on negative trials). Also, as was predicted, there was a gain in search efficiency with increasing SP. However, there were no reliable interactions involving SZ and SP (in the overall ANOVA), although Figures $3 \mathrm{~A}$ and $3 \mathrm{~B}$ suggest an interaction at least for positive trials [a separate ANOVA of the $\mathrm{RT}$ for positive trials revealed the $\mathrm{SZ} \times \mathrm{SP}$ interaction to be significant: $F(2,10)=7.09, p<.05$ ]. The advantage for large items was only evident in the intermediateand fast-speed conditions ( 30 and $37 \mathrm{msec}$, respectively), but not in the slow-speed condition $(-2 \mathrm{msec})$. In other words, at slow SP, target detection was comparatively inefficient and was not affected by SZ. Negative trials showed a significant advantage for large items at all SPs: 73,82 , and $94 \mathrm{msec}$ for the slow-, intermediate-, and fast-speed conditions, respectively.

Error data. The false-alarm rate was relatively low, $1.9 \%$ overall, which compares with an overall miss rate of $6.7 \%$. Miss and false-alarm rates were arcsine transformed and analyzed separately by three-way ANOVAs, with main terms for SZ, SP, and DS. The ANOVA of the miss rates revealed only two main terms to be significant [DS, $F(2,10)=78.07, p<.01 ; \mathrm{SZ}, F(1,5)=8.21, p<.05]$. Miss rates increased from $2.2 \%$ with 9 -item displays to $11.6 \%$ with 25 -item displays. Furthermore, they were slightly higher when the display items were small $(7.3 \%)$ rather than large $(6.1 \%)$, reinforcing the item size effect on RT. The ANOVA of the false-alarm rates revealed no significant effects.

\section{Discussion}

One question addressed by Experiment 2 was why the search rates were faster in the experiments of McLeod and his colleagues than in our previous experiments. Experiment 2 showed that, when the ratio between moving and stationary items, the SZ, and the SP of the moving items approximated those used by McLeod et al. (1991, Experiment 1), search efficiency was improved relative to the previous experiments and very similar to that in the study of McLeod et al. (1991). In their Experiment 1 with four movement directions, they found a positivetrial slope of $5 \mathrm{msec} /$ item and a negative-trial slope of $23 \mathrm{msec} /$ item. They used a 1:1 ratio between moving and stationary items, their SZ was $0.4^{\circ}$, and their moving items' SP was $3.3^{\circ}$ per second. In the present Experiment 2, the 
A) Small Item Size

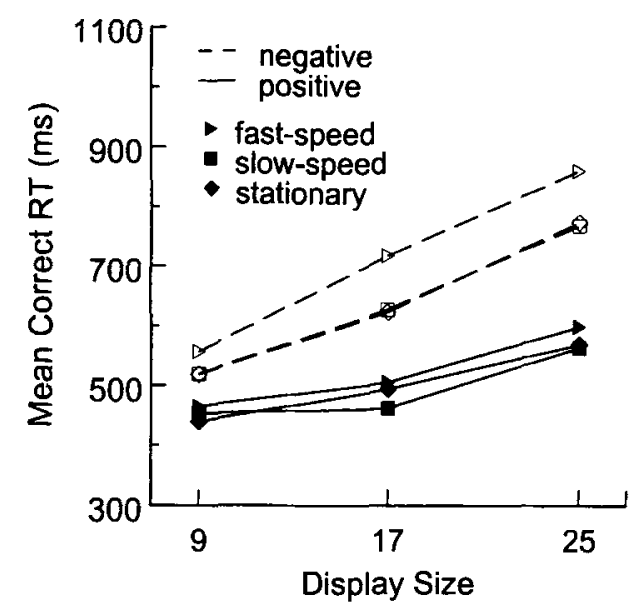

B) Large Item Size

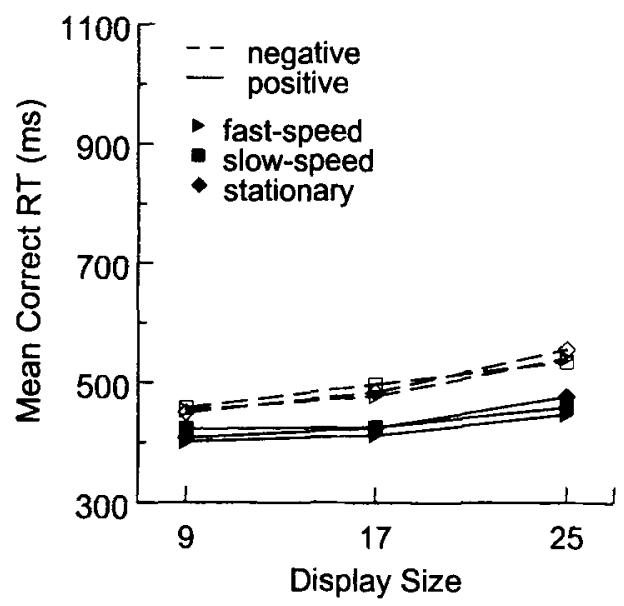

Figure 4. Mean correct reaction times (RTs) for positive and negative trials as a function of the display size, separately for each movement speed condition in Experiment 3 . Figures $4 \mathrm{~A}$ and $4 \mathrm{~B}$ present the RTs for the small item displays and the large item displays, respectively.

condition that most closely matched their display parameters (SP, $3.0^{\circ}$ per second; SZ, $0.43^{\circ}$ ) produced a search rate of $5.8 \mathrm{msec} /$ item for positive and $12.2 \mathrm{msec} / \mathrm{item}$ for negative trials.

The main question addressed by Experiment 2 concerned to what extent the visual quality of the moving items affects the search rates. Visual quality was manipulated by varying the size of the display items $\left(0.30^{\circ}\right.$ or $0.43^{\circ}$ ) and the speed of the moving items (from $1.5^{\circ} / \mathrm{sec}$ through $2.25 \% \mathrm{sec}$ to $3.0 \% \mathrm{sec}$ ). Search efficiency was expected to be greater for the larger items. Furthermore, the advantage for the larger items was predicted to be dependent on SP because the visual degradation from fast stimulus motion was expected to affect the discriminability of smaller items relatively more than that of larger items. In agreement with this hypothesis, there was no difference between positive responses when the movement speed was slow $\left(1.5^{\circ} / \mathrm{sec}\right)$; a difference was only manifest for faster SPs $(2.25 \% \mathrm{sec}$ or $3.0 \% \mathrm{sec})$.

However, seemingly at variance with the above hypothesis was the finding that overall search performance improved as a function of increasing SP. This pattern can be explained by assuming that SP has both a beneficial and a harmful effect on search performance. Increased SP is beneficial, in that it allows for a faster separation of the moving from the stationary items, owing to increased motion contrast (defined as the difference in speed between the moving and the stationary items). But increased SP is also harmful, by reducing the visual quality of the moving items (retinal smearing, etc.). The net result would be that effects of SZ are larger at higher SPs, even though the overall RTs are improved at such speeds.

\section{EXPERIMENT 3}

Although Experiment 2 suggested that the visual quality of the moving items was affected by SP, in particular that of small items, the results were not entirely conclusive, because increasing SP also enhanced search performance generally, presumably by facilitating filtering by motion (owing to increased motion contrast). If this account is correct, overall search performance should decline with increasing SP when there is no need for motionbased segmentation of the display - that is, when displays contain only moving or only stationary items.

This was investigated in Experiment 3, in which the participants searched for a simple feature target, an $\mathrm{X}$ among Os, under three motion speed conditions: $0^{\circ}$ (i.e., stationary displays), $1.5^{\circ}$, or $3.0^{\circ}$ per second. Since this task did not require filtering by motion, search efficiency was expected to decrease as a function of SP. Furthermore, as in Experiment 2, display items were either all small or all large: $0.30^{\circ}$ or $0.43^{\circ}$. If the quality of the moving items' representation in the stationary form system is impaired at higher SPs, search performance should decrease more markedly with SP for small targets than for large targets. (One could argue that, since the task does not involve filtering, all form discrimination is performed within the stationary form system. However, it is equally possible that the motion system plays a role in guiding the search to the moving items within the stationary form system even when no filtering is required.) Such an interaction is not predicted by an account according to which the crossreferencing of analyzers in the motion and form systems is affected by SP. Rather, according to this account, the 


\begin{tabular}{|c|c|c|c|c|c|c|c|c|}
\hline \multirow[b]{2}{*}{ Movement Speed } & \multicolumn{4}{|c|}{ Positive Trial } & \multicolumn{4}{|c|}{ Negative Trial } \\
\hline & RT & Rate & $R^{2}$ & $S D$ & RT & Rate & $R^{2}$ & $S D$ \\
\hline \multicolumn{9}{|l|}{ Small item size } \\
\hline Stationary & 363 & 8.1 & .81 & .21 & 367 & 15.9 & .93 & .13 \\
\hline Slow & 375 & 6.9 & .71 & .26 & 374 & 15.5 & .92 & .07 \\
\hline Fast & 380 & 8.4 & .83 & .18 & 389 & 19.0 & .95 & .09 \\
\hline \multicolumn{9}{|l|}{ Large item size } \\
\hline Stationary & 363 & 4.3 & .88 & .17 & 384 & 6.6 & .96 & .03 \\
\hline Slow & 397 & 2.3 & .75 & .27 & 414 & 4.8 & .80 & .31 \\
\hline Fast & 371 & 2.8 & .79 & .30 & 398 & 5.4 & .82 & .33 \\
\hline
\end{tabular}

reliability of the cross-referencing should be affected equally with small and large items, as long as the item density is controlled for.

\section{Method}

The same 6 participants as those who had taken part in Experiment 2 and 2 new participants took part in Experiment 3 . In contrast to the previous experiments, the participants searched for a single $X$ in a display of Os (feature search task). The DS was either 9, 17, or 25 items. Display items could be small or large, $0.30^{\circ}$ or $0.43^{\circ}$, and moved at a speed of $0^{\circ}$ (i.e., stationary condition), $1.5^{\circ}$, or $3.0^{\circ}$ per second. The experiment was subdivided into 18 blocks of 48 trials, with SZ and SP constant throughout a block. TG presence and DS were varied randomly within blocks. There were 24 trials for each combination of SZ, SP, TG presence, and DS, giving a total of 864 experimental trials. The participants performed Experiment 3 in two sessions, each starting with a practice block followed by 9 experimental blocks.

\section{Results}

Reaction time data. Figures $4 \mathrm{~A}$ and $4 \mathrm{~B}$ present the RT data for the two SZ conditions (small and large). Each figure shows the function relating the positive- and negative-trial search RTs to the total DS, separately for the three SP conditions $\left(0^{\circ}, 1.5^{\circ}\right.$, and $3.0^{\circ}$ per second $)$. The corresponding mean base RTs and mean search rates are listed in Table 5.

The base RT and search rate differences among the three SP conditions were subtle. However, an interaction between SZ and SP is evident in Figure 5, which presents the positive- and negative-trial RTs as a function of SP condition (disregarding DS), separately for two SZ conditions: Whereas large targets were detected efficiently across all SPs, search efficiency declined for small targets at SPs above $1.5^{\circ}$ per second.

A four-way ANOVA, with main terms of TG, DS, SZ, and $S P$, revealed a variety of significant main effects and interactions. Most importantly, RTs were longer for displays with fast SP than for displays with slow speed or stationary displays, particularly on negative trials [negative trials, $601 \mathrm{msec}$ vs. 568 and $567 \mathrm{msec}$; positive trials, $471 \mathrm{msec}$ vs. 464 and $468 \mathrm{msec}$; TG $\times \mathrm{SP}, F(2,14)=$ $4.35, p<.05]$. Furthermore, whereas large item displays were only little affected by SP, there was a clear effect with small item displays $[\mathrm{SZ} \times \mathrm{SP}, F(2,14)=5.68, p<$
$.05]$. Search performance exhibited little difference between stationary and slow-movement displays; however, RTs to small items were raised for fast-movement displays (see Figure 5).

Error data. Overall, participants made $4.1 \%$ misses and $1.6 \%$ false alarms. The miss and false-alarm rates were arcsine transformed and analyzed separately by threeway ANOVAs, with main terms for SZ, SP, and DS. The ANOVA of the miss rates revealed the main effects of SZ $[F(1,7)=83.53, p<.001]$ and DS $[F(2,14)=11.99, p<$ $.01]$ to be significant. Furthermore, the $\mathrm{SZ} \times \mathrm{SP}$, the $\mathrm{SZ}$ $\times \mathrm{DS}$, and the SZ $\times \mathrm{SP} \times \mathrm{DS}$ interactions $[F(4,28)=$ $4.84, p<.01]$ were significant. Miss rates increased with DS, and more misses were made with small-item displays than with large-item displays. Furthermore, the effect of SZ was larger in the fast-speed condition $(6.8 \%$ more misses with small than with large items) than in the slow-speed $(2.1 \%)$ and stationary $(3.3 \%)$ conditions. This pattern of effects was most marked with large DSs. In particular, with 25-item displays, the miss rate in the small-item, fast-movement condition was twice as large $(18.2 \%)$ as those in the stationary and slow-movement conditions $(8.9 \%$ and $6.3 \%$, respectively). Thus, the pattern of target misses reinforces the RT results (in fact, a search rate effect in the RT data may be masked by differential speed-accuracy tradeoffs among the three display conditions). The ANOVA of the false-alarm rates revealed no significant effects.

\section{Discussion}

In summary, the results were as predicted. When there was no need to filter by motion, search performance decreased as a function of SP, at least at speeds above $1.5^{\circ} / \mathrm{sec}$. This is in contrast to the findings of Experiment 2, in which the search for a moving target was facilitated with increasing SP. This dissociation between Experiments 2 and 3 suggests that, when the task requires filtering by motion, increased SP aids the segmentation of the display into stationary and moving items, probably reflecting a motion contrast effect.

Furthermore, increasing SP in Experiment 3 differentially affected the search for small and large items. Whereas large items could be detected relatively effi- 


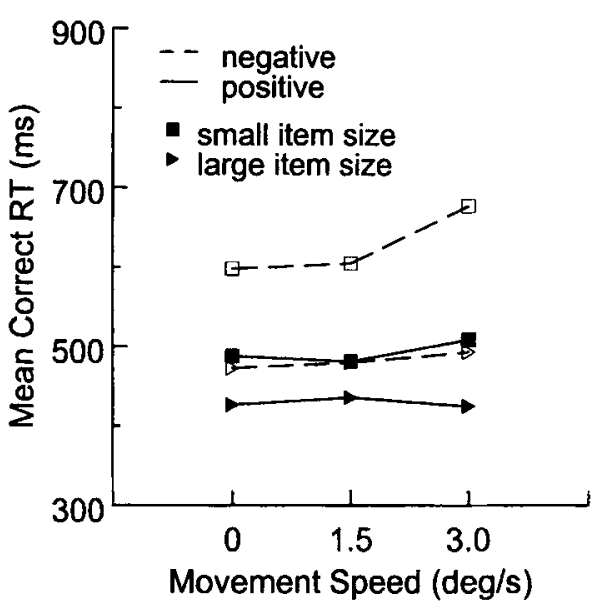

Figure 5. Mean correct reaction times (RTs) for positive and negative trials combined across display size as a function of movement speed, separately for each item size condition in Experiment 3.

ciently across all SPs, search efficiency declined clearly for the small items. This is consistent with the notion that the small items' representation in the form system deteriorated at SPs at which the large items' representation remained adequate to support efficient search. Such an interaction is not expected on the unreliable-crossreferencing account, according to which the uncertainty caused by items moving in multiple directions at high speeds ought to be relatively independent of the SZ (provided that the item density is controlled for).

Driver and McLeod (1992) discussed the possibility of visual quality loss for the moving items but dismissed it on the basis of the results of their feature search experiments, in which participants had to discriminate a target line tilted either $45^{\circ}$ or $9^{\circ}$ from the vertical nontarget lines. The participants searched for either a stationary or a moving target in displays consisting of equal numbers of stationary and moving items. Search was found to be parallel, with search rates faster than $5 \mathrm{msec} / \mathrm{item}$, in all conditions--even in the moving $9^{\circ}$ target condition, in which the target is difficult to discriminate and ought to be subject to visual quality loss. However, a closer inspection of Driver and McLeod's data revealed an interactive pattern consistent with visual quality loss for moving items. For stationary search, the search rates increased from 0 or 1 to 2 or $6 \mathrm{msec} /$ item (positive or negative responses) for $45^{\circ}$ and $9^{\circ}$ targets, respectively. For moving items, the search rates were slower and increased from 1 or 3 to 4 or $12 \mathrm{msec} /$ item. The search (moving vs. stationary) $\times$ target $\left(45^{\circ}\right.$ vs. $\left.9^{\circ}\right)$ interaction is evident in both the positive and the negative responses, although the interaction was not significant statistically. Note, however, that the feature search data probably underestimate the magnitude of the interaction, because there is no need to restrict the search to either the moving or the stationary items. In fact, the saliency of the target may be in- creased by computing the form (i.e., orientation) contrast to all display items, rather than merely to a subset of moving or stationary items (see, e.g., Cave \& Wolfe, 1990; Wolfe, 1994, 1998).

\section{GENERAL DISCUSSION}

\section{Summary of Results}

The main results of the present experiments investigating visual search for motion-form conjunction targets can be summarized as follows. (1) Search rates are primarily determined by the number of moving nontarget items (e.g., Os). Stationary nontarget items sharing the target form (e.g., Xs) also influence the search rate significantly, although their effect is only about half as strong as that of the moving nontarget items. In contrast, stationary nontargets not sharing the target form (e.g., Os) exert little or no effect on the search rates. A model that simply assumes additive contributions of moving Os, stationary Xs, and stationary Os to the search rate accounts for approximately $95 \%$ of the variability in the observed (positive) search rates. (2) Increasing the speed of the moving items $\left(>1.5^{\circ} / \mathrm{sec}\right)$ facilitates target detection if the task requires segregation of the moving from the stationary items. However, if no segregation is necessary (i.e., when all display items are moving or all are stationary), increasing SP impairs search performance. (3) Differential effects of SZ emerge only at faster SPs, or, the other way around, when the display items are large, SP has little effect on target detection. In contrast, when the display items are small, search efficiency declines when the items move faster than $1.5^{\circ} / \mathrm{sec}$.

\section{Implications for the Motion Filter Account}

The above results do not challenge the existence of some kind of motion filter. However, detailed analyses of the contributions of the various types of distractors to the overall search rate qualifies the motion filter account proposed by McLeod and his colleagues (Driver \& McLeod, 1992; McLeod et al., 1988). The finding that moving items contribute relatively more to the search rate than do stationary items would be consistent with a leaky motion filter account - that is, an extension of the account proposed by McLeod et al. (1988), which allows for some leakage of stationary items into the filter. According the leaky motion filter account, stationary items can be kept out of the search relatively efficiently, so that the search rate is determined mainly, although not exclusively, by the moving items. However, the magnitude of the moving items' effect on the search rate (above $15 \mathrm{msec} /$ item on positive trials and $30 \mathrm{msec} /$ item on negative trials) would appear to be inconsistent with the idea, advocated by Driver and McLeod, that the forms of moving items are discriminated efficiently within the motion filter. Making the alternative assumption that all form discrimination is accomplished by a unitary form system, the large contribution of the moving items to the search rates, as well as the finding that the contribution of stationary items is graded in 
terms of their form similarity to the target, becomes explicable within a framework that combines aspects of Guided Search and attentional engagement theory (e.g., Duncan \& Humphreys, 1989, 1992; Wolfe, 1994).

\section{An Alternative Account of Motion-Form Conjunction Search}

According to this alternative conceptualization, discrimination of the moving items (always) involves an interaction between the motion and the form systems, with the role of the motion system being limited to guiding (restricting) the search to the moving items. On this account, search involves the matching of item descriptions derived in early visual processing onto a responserelevant target template - that is, a top-down generated and maintained representation of the target in visual shortterm memory. If a match occurs, the target template is activated above threshold, enabling a positive target detection response to be produced. Of the two target-defining attributes, motion and form, only the latter is represented explicitly by the target template. In contrast, the motion attribute is represented only implicitly by the target template, in that the matching process is set so as to pass only, or preferentially, moving items onto the template. In brief, the target template is essentially form based in nature, whereas spatial and spatiotemporal (motion) attributes of the target are used to determine which items are matched with the target template. This account is in agreement with the proposed distinction between two functionally specialized processing pathways, the what and the where system (e.g., Desimone \& Ungerleider, 1989; Ungerleider \& Mishkin, 1982). There is evidence for the existence of something like response-related target (and nontarget) templates in the inferior temporal (IT) cortex of the monkey (Chelazzi, Miller, Duncan, \& Desimone, 1993; see also Motter, 1994a, 1994b), which is part of the occipitotemporal what pathway. Furthermore, filtering by motion has been linked to cortical area MT (e.g., McLeod, Heywood, Driver, \& Zihl, 1989; Zeki, 1993; Zihl, von Cramon, \& Mai, 1983), which is part of the occipitoparietal where pathway.

Within this framework, it can be explained why stationary items have a nonnegligible effect on the search rate and why each added moving item makes the search so much more difficult. To account for these findings, one would have to assume that (1) all display items are matched onto the target template in parallel (form-based matching); (2) moving items are weighted more strongly in the matching process (filtering by motion); and (3) the form-based coding of the moving items is in some way degraded. Assumption (1) would explain why stationary nontarget items, especially those similar in form to the target, influence search efficiency. Assumption (2) would explain why moving items contribute more to the search rate than do stationary items. Assumption (3) would explain why moving items dissimilar in form to the target exert a disproportionately strong influence on the search rate. If form-based coding were degraded for the moving items, there would be some likelihood of false matches of moving nontargets onto the target template (i.e., mistaking of nontargets for the target) and failure (or delay) of the target item to be matched (i.e., mistaking of the target for a nontarget), reducing the signal-to-noise ratio. As a result, the target would take longer to become salient, and items that achieve salience may have to be scrutinized serially (so that false matches can be rejected), delaying target detection.

The assumption that coding of moving items' form is degraded needs further justification. Form-based coding of the moving items may be degraded for two separate reasons: unreliable cross-referencing and/or reduced visual quality. Unreliable cross-referencing refers to a problem in linking the output of motion analyzers (motion system) with that of corresponding form analyzers (unitary form system). The difficulty arises because moving items continually change their positions and there may be multiple items moving in and out of the receptive field of a given motion analyzer, in particular with items moving in multiple directions. ${ }^{7}$ The more difficult the crossreferencing, the greater the need for moving items (or clusters of such items) to be checked serially, to ensure that the target is not missed. A second reason why it may be difficult to discriminate the form of the moving items is that their visual quality in the form system is reduced, at least above a certain SP and below a certain SZ. In other words, the representation of the moving items' form is noisy, owing to retinal smearing, reduced luminance contrast, and so forth. Consequently, nontargets become confusable with the target and vice versa, introducing the need to eliminate false matches and delaying target detection. The results of Experiments 2 and 3 point toward loss of visual quality as the crucial factor for the disproportionately strong influence of moving items on the search rate (while not ruling out the possibility that unreliable cross-referencing plays a role, too).

A possible implementation of the account of motionform conjunction search, which draws on assumptions underlying what Driver and McLeod (1992) have referred to as general theories of visual search, is as follows. It assumes that target selection operates from an overall saliency map (or master map of locations; see, e.g., Cave \& Wolfe, 1990; Humphreys \& Müller, 1993; Koch \& Ullman, 1985; Treisman \& Sato, 1990). The relative activation of the master map units determines the attention priority for stimuli within their receptive fields (see, e.g., Cave \& Wolfe, 1990; Koch \& Ullman, 1985; Treisman \& Sato, 1990) and/or the strength with which stimuli activate the target template in parallel (i.e., their selection weight; Duncan \& Humphreys, 1989; Humphreys \& Müller, 1993). The master map units integrate, in parallel, the output of domain-specific feature analyzers (via topographic connections between feature analyzer and master map units). Selection can be top-down controlled by enhancing the saliency of display items sharing target features, at the feature map level (e.g., Cave \& Wolfe, 1990; Treisman \& Sato, 1990; Wolfe, 1994). In con- 
junction search for a moving $X$, moving items will be activated through the motion system, and Xs through the form system, with the motion-based activation being dominant (to achieve the segmentation of the display into moving and stationary items). The moving $X$ ought to achieve a higher saliency at the master map level than do moving Os and stationary Xs, and it should more strongly activate the target template, because it is the only item receiving activation from both the motion and the form feature detectors (nontargets are supported by only one detector). Thus, in principle, search can be efficiently guided to the moving target even when there are stationary items in the display sharing the target form. However, the moving item's representation in the form system may be degraded, lowering the form-based activation of the moving (target) $\mathrm{X}$ and raising that of moving (nontarget) Os; and/or the cross-referencing of motion-based signals with form-based signals at the master map level may be imprecise spatially, so that stationary and moving stimuli being passed, in close proximity, by other (moving) stimuli temporarily attract motion-based enhancement from, or lose motion-based enhancement to, the other (moving) stimuli. Both factors would decrease the signal-to-noise ratio at the master map level (by affecting form-based enhancement and increasing the variability of motionbased enhancement), delaying target detection.

Within this framework, an adaptive mechanism making search performance sensitive to the ratios between the numbers of stationary Xs and moving Os in the display (see the Discussion section for Experiment 1; see also Kaptein et al., 1995; Poisson \& Wilkinson, 1992; Zohary \& Hochstein, 1989) can be accommodated as follows. Assume that the total amount of top-down enhancement is fixed for the motion system and fixed for the form system and that equal shares of enhancement are allocated to moving items within the motion system and to items sharing the target form (Xs) within the form system. Thus, the less the number of items represented in either system, the greater their share of enhancement. As a result, if the numbers of items represented in the two systems are unequal, the smaller set of items will achieve a higher activation within the overall activation map, thus guiding the search to that set of items. In other words, the adaptive mechanism could, in principle, operate in a completely automatic fashion, without top-down intervention, although top-down influences are by no means ruled out. (See also Wolfe, 1994, who simulated the Zohary \& Hochstein results, using an implementation of the Guided Search 2.0 model.)

This account of motion-form conjunction search is parallel-continuous in the sense that the distribution of activity in the selection-relevant overall saliency map is a parallel-continuous function of the numbers of items represented within the motion and form systems, as well as their ratio. This account is distinguished from the discrete two-stage account of McLeod and his colleagues (Driver \& McLeod, 1992; McLeod et al., 1988; McLeod et al., 1991), according to which a nonleaky motion filter segregates the moving from the stationary items at the first stage, followed by form-based processing of the moving items only at the second stage.

In conclusion, a relatively simple eclectic model that combines aspects of general theories of visual searchmost notably, Guided Search and attentional engagement theory-Can provide a satisfactory framework within which to account for motion-form conjunction search. However, general theories cannot fully account for the present data without specifying the mechanisms by which motion speed exerts differential effects on the motion system (beneficial, owing to enhanced motion contrast) and the form discrimination system (potentially harmful, depending on the size of the display items). In this sense, Driver and McLeod (1992) are right in arguing that, for a full understanding of visual search performance, "General theories . . . will have to take the specific properties of different visual subsystems into account" (p. 32).

\section{REFERENCES}

Berger, R. C., \& MCLeod, P. (1996). Display density influences visual search for conjunctions of movement and orientation. Journal of Experimental Psychology: Human Perception \& Performance, 22, 114 121

CAVE, K. R., \& WolfE, J. M. (1990). Modeling the role of parallel processing in visual search. Cognitive Psychology, 22, 225-27l.

Chelazzi, L., Miller, E. K., Duncan, J., \& Desimone, R. (1993). A neural basis for visual search in inferior temporal cortex. Nature, 363 , 345-347.

Cohen, J., \& Cohen, P. (1983). Applied multiple regression/correlation analysis for the behavioral sciences (2nd ed.). Hillsdale, $\mathrm{NJ}$ : Erlbaum.

Desimone, R., \& Ungerleider, L. G. (1989). Neural mechanisms of visual processing in monkeys. In F. Boller \& J. Grafman (Eds.), Handbook of neuropsychology (Vol. 2, pp. 267-299). Amsterdam; Elsevier.

DRIVER, J., \& MCLEOD, P. (1992). Reversing visual search asymmetries with conjunctions of movement \& orientation. Journal of Experimental Psychology: Human Perception \& Performance, 18, 22-33.

Duncan, J. (1995). Target and nontarget grouping in visual search. Perception \& Psychophysics, 57, 117-120.

DunCan, J., \& Humphreys, G. W. (1989). Visual search and stimulus similarity. Psychological Review, 96, 433-458.

Duncan, J., \& Humphreys, G. W. (1992). Beyond the search surface: Visual search and attentional engagement. Journal of Experimental Psychology: Human Perception \& Performance, 18, 578-588.

EgETh, H. E., Virzl, R. A., \& GarbarT, H. (1984). Searching for conjunctively defined targets. Ioumal of Experimental Psychology: Human Perception \& Performance, 10, 32-39.

FinLEY, G. (1985). A high-speed point plotter for vision research. $V_{i}$ sion Research, 25, 1993-1997.

Humphreys, G. W., \& Müller, H. J. (1993). Search via Recursive Rejection (SERR): A connectionist model of visual search. Cognitive Psychology, 25, 43-110.

Kaptein, N. A., Theeuwes, J., \& Van der Heijden, A. H. C. (1995). Search for a conjunctively defined target can be selectively limited to a color-defined subset of elements. Journal of Experimental Psychology: Human Perception \& Performance, 21, $1053-1069$.

Косн, C., \& Ullman, S. (1985). Shifts in selective visual attention: Towards the underlying neural circuitry. Human Neurobiology, 4, 219 227.

MCleod, P., Driver, J., \& Crisp, J. (1988). Visual search for a conjunction of movement and form is parallel. Nature, 332, 154-155.

McLeod, P., Driver, J., Dienes, Z., \& CrisP, J. (1991). Filtering by movement in visual search. Journal of Experimental Psychology: Human Perception \& Performance, 17, 55-64.

Mcleod, P., Heywood, C., Driver, J., \& ZIHL, S. (1989). Selective deficit of visual search in moving displays after extrastriate damage. Nature, 933, 466-467.

MotTer, B. C. (1994a). Neural correlates of feature selective memory 
and popout in extrastriate area V4. Journal of Neuroscience, 14, 2178-2189.

MotTer, B. C. (1994b). Neural correlates of attentive selection for color or luminance in extrastriate area V4. Journal of Neuroscience, 14, 2190-2199.

Mǘler, H. J., \& Found, A. (1996). Visual search for conjunctions of motion and form: Display density and asymmetry reversal. Journal of Experimental Psychology: Human Perception \& Performance, 22, 122-132.

Müller, H. J., \& MAXWEll, J. (1994). Perceptual integration of motion and form information: Is the movement filter involved in form discrimination? Journal of Experimental Psychology: Human Perception \& Performance, 20, 397-420.

MülleR, H. J., \& VON MühLENEN, A. (1999). Visual search for conjunctions of motion and form: The asymmetry for easy-to-discriminate targets depends on practice. Visual Cognition, 6, 385-408.

Nakayama, K., \& Silverman, G. (1986). Serial and parallel processing of visual feature conjunctions. Nature, 320, 264-265.

Poisson, M. E., \& Wilkinson, F. (1992). Distractor ratio and grouping processes in visual conjunction search. Perception, 21, 21-38.

Segalowitz, S. J., \& Graves, R. E. (1990). Suitability of the IBM XT, $\mathrm{AT}$, and PS/2 keyboard, mouse, and game port as response devices in reaction time paradigms. Behavior Research Methods, Instruments, \& Computers, 22, 283-289.

Treisman, A., \& Gelade, G. (1980). A feature-integration theory of attention. Cognitive Psychology, 12, 97-136.

Treisman, A., \& Sato, S. (1990). Conjunction search revisited. Journal of Experimental Psychology: Human Perception \& Performance, 16, 459-478.

Ungerleider, L. G., \& Mishkin, M. (1982). Two cortical visual systems. In D. J. Ingle, M. A. Goodale, \& R. J. W. Mansfield (Eds.), Analysis of visual behavior (pp. 549-586). Cambridge, MA: MIT Press.

VON MÜHLENEN, A. (1997). The integration of motion and form in visual perception. Unpublished doctoral dissertation, University of Berne, Switzerland.

Von Mühlenen, A., \& Müller, H. J. (1999). Visual search for motion-form conjunctions: Selective attention to movement direction. Journal of General Psychology, 126, 289-317.

WOLFE, J. M. (1994). Guided Search 2.0: A revised model of visual search. Psychonomic Bulletin \& Review, 1, 202-238.

Wolfe, J. M. (1998). Visual search. In H. Pashler (Ed.), Attention (pp. 13-73). Hove, U.K.: Psychology Press.

Wolfe, J. M., Cave, K. R., \& Franzel, S. L. (1989). Guided search: An alternative to the feature integration model for visual search. Journal of Experimental Psychology: Human Perception \& Performance, $15,419-433$.

ZEKI, S. (1993). A vision of the brain. London: Blackwell Scientific Publications.

ZiHL, J., von CRAMON, D., \& MAI, N. (1983): Selective disturbance of movement vision after bilateral brain damage. Brain, 106, 313-340.

ZohaRY, E., \& HochSTEIN, S. (1989). How serial is serial processing in vision? Perception, 18, 191-200.

\section{NOTES}

1. Following Driver and McLeod (1992), the term general theories is meant to refer to all theories that "account for visual search across a wide range of stimulus attributes, [without] invoking the specific properties of different visual subsystems to explain the results of particular experiments" (p. 23).

2. The study was designed to examine the influence of the number of movement directions and of advance knowledge of the target movement direction on search performance.

3. The displays of moving items moving in four orthogonal directions, with the target direction being unpredictable, are different from those used by McLeod et al. (1988, Experiment 1: one direction only, upward) but similar to those employed by McLeod et al. (1991, Experiment 1: four directions). McLeod and his colleagues found little dif- ference in positive search rates when there was only one movement direction ( $3 \mathrm{msec} / \mathrm{item}$ ), as compared with when there were four directions and the target direction was unpredictable $(5 \mathrm{msec} /$ item $)$. See also von Mühlenen and Müller (1999, Experiment 1), who reported positive search rates of 11.8 and $12.5 \mathrm{msec} / \mathrm{item}$ with one and four movement directions, respectively. The use of four movement directions, with unknown target direction, was considered preferable to single-direction displays, because it guards against confounding variables, such as the clustering of the moving items in parts of the display (e.g., in the lower half at display onset when all items move upward; see Driver \& McLeod, 1992, and McLeod et al., 1988) and eye movements to the parts anticipated to contain a target.

4. A pilot experiment presenting stationary items only was carried out to ascertain that the form discrimination required in the subsequent experiments could be performed in parallel. The task required detection of a stationary $X$ among stationary $O$ s in displays containing 9,17 , or 25 items. The search rates of 6 participants averaged $2.3 \mathrm{msec} /$ item on positive trials and $4.3 \mathrm{msec} / \mathrm{item}$ on negative trials, indicating that the form discrimination was indeed easy.

5 . The increase in display area with increasing item number is in contrast to McLeod et al. (1991, Experiment 1), whose display area was constant at $11^{\circ} \times 8^{\circ}$. One potential problem with their procedure is that the item density varied as a function of the DS. There is an unavoidable tradeoff between item density and the size of the display area. Which display parameter is more important to control for in motion-form conjunction search is debatable (Berger \& McLeod, 1996; Müller \& Found, 1996).

6. In Tables 2 and 3 , the $\beta$ weights increased in Steps $1-3$ as the SX and $\mathrm{SO}$ variables were entered into the regression equation. However, $\beta$ weights typically decrease (or stay the same) when new variables are entered. The fact that they increased suggests that suppression effects were affecting the outcome of the regression (Cohen \& Cohen, 1983). To assess the influence of suppression effects, one has to examine the individual correlations between the predictor variables and the RTthat is, $r$ (MO, RT), $r(\mathrm{SX}, \mathrm{RT})$, and $r$ (SO,RT). For the positive trials, whereas $r$ (MO,RT) was highly significant $(r=.86, p<.001)$ and $r(\mathrm{SO}, \mathrm{RT})$ was insignificant $(r=-.25), r(\mathrm{SX}, \mathrm{RT})$ was marginally significant ( $r=.40, p=.052$; one-tailed tests). A similar pattern of results was found for the negative trials $[r(\mathrm{MO}, \mathrm{RT})=.72, p<.01 ; r(\mathrm{SO}, \mathrm{RT})=$ $.51, p<.025$; and $r$ (SO,RT) $=-.06$, n.s.]. Importantly, although $r(\mathrm{SX}, \mathrm{RT})$ was only marginally significant for the positive trials, it was significant for the negative trials (one-tailed significance tests were justified, since moving $\mathrm{O}$ and stationary $\mathrm{X}$ distractors each share a targetdefining feature, predicting positive correlations with RT). Thus, the individual correlations are in line with the stepwise regression analysis, according to which moving Os are the most important determinant of the search rates, with stationary Xs also exerting a reliable (albeit, reduced) effect. This pattern of results was replicated in an unpublished experiment (von Mühlenen, 1997, Experiment 5), which presented different proportions of the various types of nontarget to those used in Experiment 1 . In summary, although suppression effects may have affected the outcome of the regression analysis of Experiment 1, there are good grounds on which to conclude that the search rates are determined by both moving Os and stationary Xs.

7. The amount of interference would depend on the size of the motion analyzers' receptive fields and how narrowly they are tuned to a specific direction. According to Zeki (1993), the receptive fields of motionsensitive cells in cortical area MT/V5 of the monkey vary considerably in size, from $1.5^{\circ} \times 1.5^{\circ}$ up to $45^{\circ} \times 33^{\circ}$; most cells exhibit directional preferences, although a few cells are motion selective but not directionally selective. Recall that items in the present experiments were displayed within a square matrix with cells of size $1.2^{\circ} \times 1.2^{\circ}$, which is close to the small receptive field sizes of MT/V5 cells. In other words, most cells would have had more than one moving item in their receptive fields at some time during a trial.

(Manuscript received June 3, 1998; revision accepted for publication March 29, 1999.) 